Article

\title{
Ammonium Hydroxide Mediated Hydrothermal Crystallization of Hydroxyapatite Coatings on Titanium Substrate
}

\author{
Katarzyna Suchanek ${ }^{1, *(\mathbb{D}}$, Marcin Perzanowski ${ }^{2}$, Janusz Lekki ${ }^{2}{ }^{\circ}$, Martyna Strag $^{3}$ and \\ Marta Marszałek ${ }^{2}$ (D) \\ 1 Institute of Physics, Cracow University of Technology, Podchorążych 1, 30-084 Kraków, Poland \\ 2 The Institute of Nuclear Physics Polish Academy of Sciences, Radzikowskiego 152, 31-342 Krakow, Poland; \\ marcin.perzanowski@ifj.edu.pl (M.P.); Janusz.Lekki@ifj.edu.pl (J.L.); marta.marszalek@ifj.edu.pl (M.M.) \\ 3 The Institute of Metallurgy and Materials Science Polish Academy of Sciences, Reymonta 25, 30-059 Krakow, \\ Poland; martynastrag@gmail.com \\ * Correspondence: katarzyna.suchanek@pk.edu.pl; Tel.: (+48-12)-637-06-66
}

Received: 1 February 2019; Accepted: 15 March 2019; Published: 19 March 2019

\begin{abstract}
Controlled growth of hydroxyapatite (HAp) coatings on titanium substrate plays an important role in the fabrication of the composites for bone tissue engineering. We describe the synthesis of the crystalline hydroxyapatite coatings on the $\mathrm{Ti} / \mathrm{TiO}_{2}$ substrate through a hydrothermal method by using ethylenediamine tetraacetic acid disodium salt $\left(\mathrm{Na}_{2} \mathrm{EDTA}\right)$ and varying concentrations of ammonium hydroxide $\left(\mathrm{NH}_{4} \mathrm{OH}\right)$ in calcium-phosphate precursor solution. $\mathrm{Na}_{2}$ EDTA serves as a chelating agent, while $\mathrm{NH}_{4} \mathrm{OH}$ is used as an alkaline source and crystal growth modifier. We characterized the HAp coatings using x-ray diffraction, scanning electron microscopy, and Raman spectroscopy. We also performed the elemental chemical analysis by means of a particle induced $\mathrm{x}$-ray emission method. Our results show that there is a $\mathrm{pH}$ limit for which the hydrothermal deposition of HAp on titanium occurs. Moreover, we observed that $\mathrm{NH}_{4} \mathrm{OH}$ had a measurable influence on the coating thickness as well as on the size and shape of the HAp crystals. We found that with the increase of $\mathrm{NH}_{4} \mathrm{OH}$ concentration, the thickness of the Hap layer increases and its morphology changes from irregular flakes to well-defined hexagonal rods.
\end{abstract}

Keywords: hydroxyapatite coatings; hydrothermal synthesis; ammonium hydroxide

\section{Introduction}

Calcium phosphates, in particular hydroxyapatite ( $\left.\mathrm{HAp}, \mathrm{Ca}_{10}\left(\mathrm{PO}_{4}\right)_{6}(\mathrm{OH})_{2}\right)$, form the mineral constituent of hard tissues [1]. HAp coatings on the titanium substrates have excellent biocompatibility and osteoconductivity, and therefore are widely applied in the correction of bone defects caused by traumas, diseases, and genetic disorders [2]. Geometrical factors such as shape and dimensions of HAp crystals have a significant impact on their biological response and mechanical properties under load bearing conditions [3,4]. Numerous deposition techniques of HAp on metallic substrates have been described, such as plasma spraying [5,6], electrophoresis [7], sol-gel [8], magnetron sputtering [9], and the hydrothermal method [10]. However, it is still a challenge to obtain HAp coatings with desirable properties, in particular HAp crystals with well-defined morphology and precisely adjustable sizes. Development of a method for controlled growth of the HAp coatings would help with the realization of the new concept of biomaterials: materials which regulate cellular responses and enhance bone mineralization.

The hydrothermal approach has been proven to be an effective and convenient process in preparing HAp powders. During the synthesis carried out in an autoclave at elevated temperature 
and elevated pressure, crystalline HAp coatings with a $\mathrm{Ca} / \mathrm{P}$ ratio close to the stoichiometric value were obtained [10]. Depending on the reaction mechanism, several pathways for hydrothermal crystallization of HAp can be distinguished, i.e.: (i) chelate decomposition [11-14], (ii) urea decomposition $[15,16]$, (iii) dissolution-precipitation of calcium phosphate precursor $[17,18]$, and others [19]. The chelate decomposition technique, used herein, is based on chemical precipitation of HAp phase from solution containing calcium and phosphate sources. Additionally, an organic modifier is added, usually a chelating agent such as ethylenediamine tetraacetic acid (EDTA), to adjust the concentration of free $\mathrm{Ca}^{2+}$ ions, and therefore to control the nucleation and growth of the HAp crystals [12-14,20]. At room temperature, EDTA immediately forms stable Ca-EDTA complex, depleting the stock solution of free $\mathrm{Ca}^{2+}$ ions. However, at hydrothermal conditions, i.e., increased temperature and pressure, the equilibrium state shifts towards the Ca-EDTA dissociation, releasing the $\mathrm{Ca}^{2+}$ ions and consequently the precipitation of calcium phosphate phase appears. Crystal growth during the hydrothermal process is regulated not only by the chelating agent, but also by the $\mathrm{pH}$ of the reacting solution. The $\mathrm{pH}$ affects the equilibrium state in the reacting medium and the solubility of the HAp phase. The impact of the complexing agent as well as of $\mathrm{pH}$ on the morphology of the HAp powders in chelate decomposition synthesis is well known [20-22]. HAp powders of flower-like nanostructures, nanorod aggregates, dumbbell-like nanostructures, hexagonal prism-like nanorods, whiskers, and nanowires can be obtained depending on the used reactants and surfactants. However, the effect of $\mathrm{pH}$ on the heterogeneous nucleation and growth of $\mathrm{HAp}$ coatings on the $\mathrm{Ti} / \mathrm{TiO}_{2}$ substrate is less understood. The process is, as described, complex and $\mathrm{pH}$ also influences the physicochemical properties of the $\mathrm{Ti} / \mathrm{TiO}_{2}$ surface on which HAp crystals nucleate and grow [23]. Pioneering research in this field was carried out by Fujishiro et al. [24,25]. These authors synthesized HAp on titanium and other metallic substrates using the chelate decomposition method and $\mathrm{NaOH}$ as alkalizing agent. As a result, plate-like monetite and needle-like hydroxyapatite crystals were obtained at $\mathrm{pH}<7.0$. The crystals were irregular in shape and the surface of the substrate was not homogeneously covered. Above this $\mathrm{pH}$, the crystals did not grow. The application of the appropriate seeding layer made it possible to obtain a dense coating at a higher $\mathrm{pH}$. More recently, adequate HAp crystal morphology in the coatings synthesized hydrothermally was obtained also through a suitable seeding layer [26-28]. $\mathrm{Lu}$ et al. showed that the use of the glass substrate with a $\mathrm{ZnO}$ seed layer leads to the oriented growth of the hydroxyapatite nanorod array [26]. Chen et al. fabricated HAp coatings with oriented nanorod arrays by using the bioglass as precursors [27]. Uniform, highly crystalline HAp coatings have also been deposited on grafted titanium substrate as shown by Shen et al. [28]. A self-assembly technique was applied to introduce functional groups on titanium which served as nucleation sites for apatite crystals.

In this study we investigate the effect of ammonia hydroxide concentration on the nucleation and growth of the HAp coatings on the $\mathrm{Ti} / \mathrm{TiO}_{2}$ substrate. The issue of the alkalizing agent seems to be important; as has been recently shown by Li et al. [29] the size of HAp particles could be controlled by alkaline reagent. We show that alkalinity adjusted by ammonia solution has measurable influence on the coatings thickness, and on the size and shape of HAp crystals, as well as on the crystal growth rate on the titanium surface.

\section{Materials and Methods}

\subsection{Titanium Substrate Preparation}

Commercially available pure titanium sheet (BIMO Metals, Wrocław, Poland) with a thickness of $3 \mathrm{~mm}$ was cut into square samples with dimensions of $10 \times 10 \mathrm{~mm}^{2}$. The samples were cleaned with acetone and alcohol in an ultrasonic bath and rinsed with ultrapure water $\left(18.2 \mathrm{M} \Omega \cdot \mathrm{cm}^{-1}\right)$ from a Polwater system. The cleaned Ti plates were firstly soaked in a mixture of $\mathrm{H}_{2} \mathrm{SO}_{4}\left(6.3 \mathrm{~mol} \cdot \mathrm{dm}^{-3}\right)$ and $\mathrm{HCl}\left(1.8 \mathrm{~mol} \cdot \mathrm{dm}^{-3}\right)$ solution in a weight ratio of $1: 1$ at $70{ }^{\circ} \mathrm{C}$ for $1 \mathrm{~h}$, then treated in oxidizing conditions 
at $650{ }^{\circ} \mathrm{C}$ to form a $\mathrm{TiO}_{2}$ layer according to the method described in reference [10]. The as-prepared $\mathrm{Ti} / \mathrm{TiO}_{2}$ substrates were further used for hydrothermal synthesis.

\subsection{Chemical Synthesis}

In a typical synthesis procedure calcium nitrate $\mathrm{Ca}\left(\mathrm{NO}_{3}\right)_{2}\left(0.2 \mathrm{~mol} \cdot \mathrm{dm}^{-3}\right)$ and diammonium phosphate $\left(\mathrm{NH}_{4}\right)_{2} \mathrm{HPO}_{4}\left(0.12 \mathrm{~mol} \cdot \mathrm{dm}^{-3}\right)$ were individually dissolved in ultrapure water. Ethylenediamine tetraacetic acid (EDTA) was added to the calcium solution as a chelating agent with fixed molar ratio of EDTA:Ca ${ }^{2+}$ (1:1). When the reactants were entirely mixed, the two solutions were combined and subsequently stirred at room temperature for $30 \mathrm{~min}$. Next, the ammonium hydroxide $\left(\mathrm{NH}_{4} \mathrm{OH}\right)$ was added drop-wise. To study the effect of $\mathrm{pH}$ variation on the HAp crystal growth, the molar concentration of $\mathrm{NH}_{4} \mathrm{OH}$ was set to a specific value ranging from 0.2 to $1.34 \mathrm{~mol} \cdot \mathrm{dm}^{-3}$, causing $\mathrm{pH}$ changes from 6.0 to 10.5. The five final solutions were labelled as $\mathrm{CaPx}$ (where $\mathrm{x}=0.2,0.27,0.4$, $0.8,1.34$, and denotes the $\mathrm{NH}_{4} \mathrm{OH}$ concentration), transferred into $200 \mathrm{~mL}$ Teflon vessels and put into hydrothermal reactor (Carl Roth 2098.1). The titanium substrate was placed on a special holder at an angle of $45^{\circ}$ to the bottom of the container. The holder was put inside the glass vessel in such a way that samples were completely immersed in the solution. The autoclave was sealed and set up to $200{ }^{\circ} \mathrm{C}$ for $7 \mathrm{~h}$. After the synthesis samples were gently rinsed with ultrapure water and left to dry at room temperature.

\subsection{Characterization}

The surface morphology of the as-deposited HAp coatings was examined using scanning electron microscope (SEM, Tescan Vega 3). The crystal structure was determined with an x-ray diffractometer (XRD, PANalytical X'Pert Pro) operating at $30 \mathrm{~mA}$ and $40 \mathrm{kV}$. The radiation wavelength $\left(\mathrm{Cu} \mathrm{K}_{\alpha}\right)$ was $1.54 \AA$. X-ray diffraction patterns were taken over the $2 \theta$ range of $20^{\circ}-80^{\circ}$ with a $0.05^{\circ}$ step size. The angular resolution of the instrument was calibrated using the LaB6 line profile standard (SRM660a-NIST certificate). The chemical composition of the HAp coatings was determined with Raman spectrometer (Almega XR of Thermo Electron Corp.). A $532 \mathrm{~nm}$ laser was used to excite the Raman signal. The data were recorded in the spectral range from 100 to $4000 \mathrm{~cm}^{-1}$ with spectral resolution of $2 \mathrm{~cm}^{-1}$. The elemental analysis was performed using energy dispersive $x$-ray spectrometer (QUANTAX EDS, Bruker) equipped with an XFlash 610M detector with the resolution of $<129 \mathrm{eV}$ for the $\mathrm{Mn} \mathrm{K} \alpha$ line. Chemical composition of the samples was measured using particle induced $\mathrm{x}$-ray emission (PIXE) technique. The $\mu$ PIXE analysis was performed using $2 \mathrm{MeV}$ protons from the electrostatic Van de Graaff accelerator, at the Institute of Nuclear Physics, Polish Academy of Sciences, Cracow (IFJ PAN). Rectangular areas $\left(0.25 \times 0.25 \mathrm{~mm}^{2}\right)$ were scanned with the beam of approx. $20 \mu \mathrm{m}$ in diameter. The semiconductor $\mathrm{Si}(\mathrm{Li})$ detector, with the resolution of $160 \mathrm{eV}$ for the energy of $5.9 \mathrm{keV}$ and the active area of $80 \mathrm{~mm}^{2}$, was placed $25 \mathrm{~mm}$ away from the irradiated sample and was operating without any attenuation filter.

\section{Results}

Figure 1 shows $\mathrm{SEM}$ images of the $\mathrm{Ti} / \mathrm{TiO}_{2}$ surfaces after the hydrothermal treatment in calcium-phosphate precursor solution with various ammonium hydroxide molar concentrations. The development of hexagonal rods with well-defined geometry is clearly visible in the consecutive top view SEM images (Figure $1 \mathrm{f}-\mathrm{j})$. For sample with the lowest concentration of ammonia $(\mathrm{CaPx}=$ 0.2 ), no crystal growth was observed on the $\mathrm{Ti} / \mathrm{TiO}_{2}$ surface (Figure 1f). At $\mathrm{pH}=7.2(\mathrm{CaPx}=0.27)$, irregular HAp crystals in the form of plates were sparsely formed (Figure 1g). The width of plates varies from 0.1 to $0.8 \mu \mathrm{m}$. A further increase in $\mathrm{pH}$ led to the growth of HAp crystals with hexagonal symmetry. We observed the aggregated rods of about $0.35 \mu \mathrm{m}$ in diameter for $\mathrm{CaPx}=0.4$ (Figure $1 \mathrm{~h}$ ), for higher $\mathrm{pH}$ we observed the separate hexagonal rods with $0.55 \mu \mathrm{m}$ in diameter (Figure 1i), and for the highest $\mathrm{pH}$ value we registered the well-defined hexagonal crystals of about $0.95 \mu \mathrm{m}$ in diameter (Figure 1j). Figure 2a illustrates the diameters of hexagonal HAp crystals as a function of the $\mathrm{pH}$ value. 
We also performed the cross-sectional SEM imaging which allowed us to estimate the thickness of the HAp coatings using the ImageJ open source program (Figure 1k-o). In these images the layered structure of the $\mathrm{Ti} / \mathrm{TiO}_{2} / \mathrm{HAp}$ systems is clearly visible. The results show that the $\mathrm{pH}$ of the reacting solution affects the crystal growth rate; the higher $\mathrm{pH}$, the thicker is the HAp coating. The thickest hydroxyapatite coatings of approximately $50 \mu \mathrm{m}$ were grown at $\mathrm{pH}=10.5$. The thicknesses of the HAp layers produced at various ammonia concentrations are summarized in Table 1 and shown in Figure 2a. The elemental distribution of each sample was analyzed by EDS spectrometry. The results are shown in Figure 1 a-e and are included in Table 1. EDS analysis of $\mathrm{Ti} / \mathrm{TiO}_{2} / \mathrm{HAp}$ structures confirmed the presence of $\mathrm{Ca}$ and $\mathrm{P}$. The calculated $\mathrm{Ca} / \mathrm{P}$ relative atomic ratio was $1.51,1.57,1.69$ and 1.74 for $\mathrm{CaPx}=$ $0.27, \mathrm{CaPx}=0.4, \mathrm{CaPx}=0.8$ and $\mathrm{CaPx}=1.34$, respectively. The $\mathrm{Ca} / \mathrm{P}$ values for samples synthesized at $\mathrm{pH} \geq 9.0$ within the margin of experimental error are in good agreement with the theoretical data on the stoichiometry of the HAp phase. A minor deviation from the nominal composition observed for the $\mathrm{CaPx}=0.27$ sample may suggest that the synthesized crystals contained more defects, or that the hydroxyapatite was calcium deficient. However, it should be noted that for this sample the calcium and phosphorus elemental content was very low.

Strong inhibition of crystal growth shown in the SEM image for low $\mathrm{pH}(\mathrm{pH}<7)$ could be due to the fact that the coating precipitation under hydrothermal conditions is a complex phenomenon and $\mathrm{pH}$ of the solution also affects the chemical nature of the $\mathrm{Ti} / \mathrm{TiO}_{2}$ substrate itself. We intentionally created the $\mathrm{TiO}_{2}$ layer on $\mathrm{Ti}$ since the surface of titanium oxide in aqueous medium exhibits surface charge strongly depending on the $\mathrm{pH}$ of solution. Surface charge can promote crystal nucleation, and the electrostatic attraction may be the driving force for the nucleation process of HAp [30,31]. The isoelectric point (IEP) for $\mathrm{TiO}_{2}$ varies between 5 and 6.5 depending on the crystal phase [32], which means that in the acidic environment $(\mathrm{pH}<7)$, the adsorption of functional groups on titanium is limited. This effect is well demonstrated in SEM images: at low $\mathrm{pH}$ the HAp nucleation is limited, while a further increase in $\mathrm{pH}$ intensifies the crystal growth rate.

The crystal structure and phase purity of the HAp coatings were examined by XRD (Figure 3a). For sample prepared at $\mathrm{pH}=6.0$ we observed exclusively $\alpha$-Ti and crystalline $\mathrm{TiO}_{2}$ with the tetragonal rutile structure, originating from the substrate. For other samples, the XRD analysis indicated the presence of the hexagonal HAp phase with the space group $\mathrm{P} 63 / \mathrm{m}$, irrespective of the $\mathrm{NH}_{4} \mathrm{OH}$ addition as a pH modifier. The calculated lattice parameters were $\mathrm{a}=9.44(2) \AA, \mathrm{c}=6.89(2) \AA$; these are in good agreement with the literature data [33]. No other calcium phosphate phases, such as TCP or $\mathrm{OCP}$, were observed.

Table 1. Hydrothermal synthesis parameters; estimated HAp layer thickness.

\begin{tabular}{|c|c|c|c|c|}
\hline Sample & $\begin{array}{c}\mathrm{NH}_{4} \mathrm{OH} \\
\text { Concentration } \\
{\left[\mathrm{mol} \cdot \mathrm{dm}^{-3}\right]}\end{array}$ & $\mathrm{pH}$ & $\begin{array}{c}\text { HAp Layer Thickness } \\
\text { Mean Value (SD) * }(n=6) \\
{[\mu \mathrm{m}]}\end{array}$ & Ca/P Molar Ratio \\
\hline $\mathrm{CaPx}=0.2$ & 0.2 & 6.0 & - & - \\
\hline $\mathrm{CaPx}=0.27$ & 0.27 & 7.2 & $16.5(2.4)$ & $1.51(0.10)$ \\
\hline $\mathrm{CaPx}=0.4$ & 0.4 & 9.0 & $16.9(3.1)$ & $1.57(0.10)$ \\
\hline $\mathrm{CaPx}=0.8$ & 0.8 & 10.0 & $29.5(1.3)$ & $1.69(0.11)$ \\
\hline $\mathrm{CaPx}=1.34$ & 1.34 & 10.5 & $48.2(5.2)$ & $1.74(0.11)$ \\
\hline
\end{tabular}

* SD corresponds to standard deviation. 

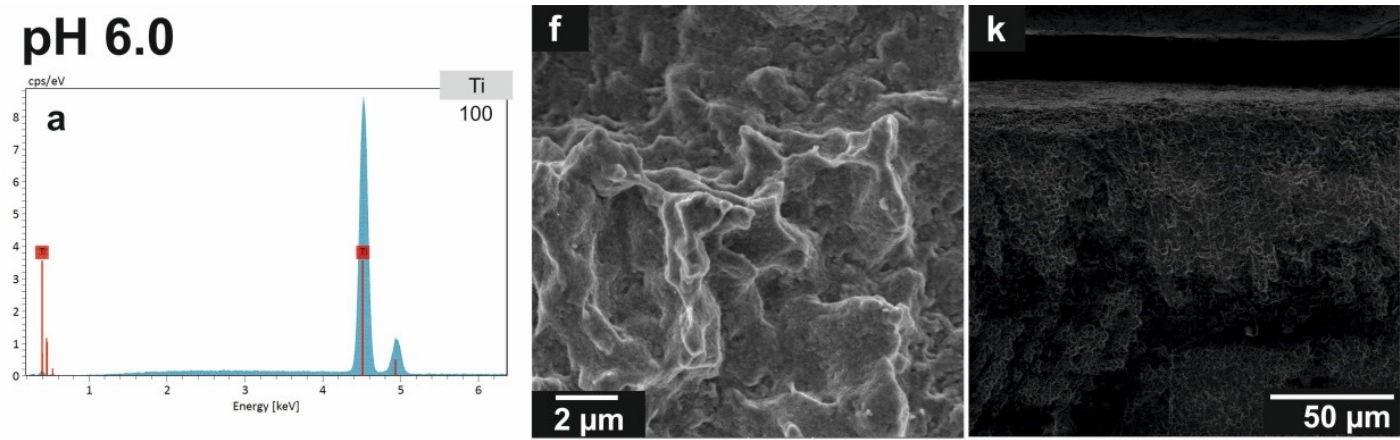

\section{pH 7.2}
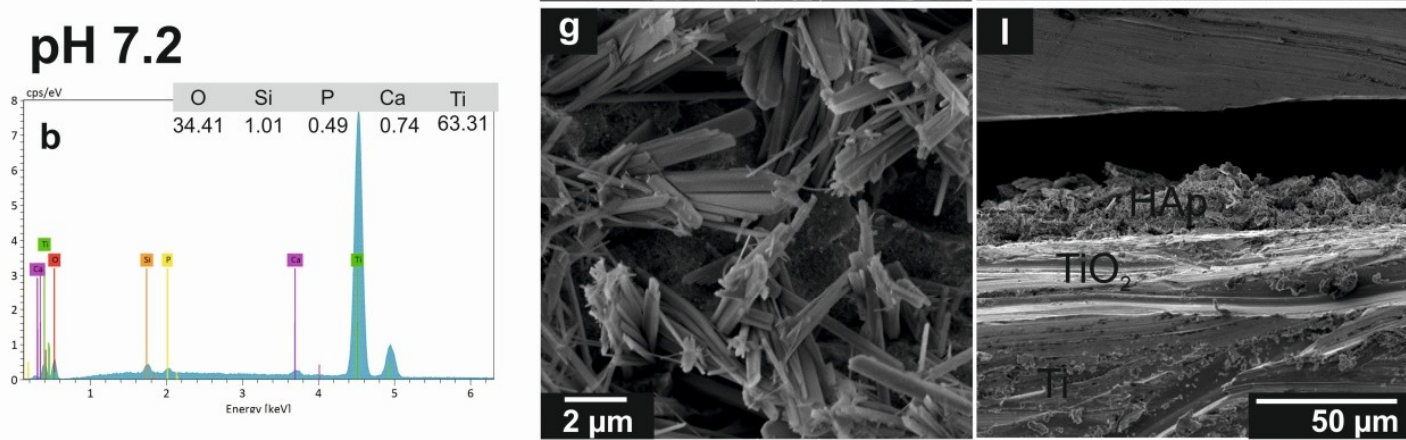

\section{pH 9.0}

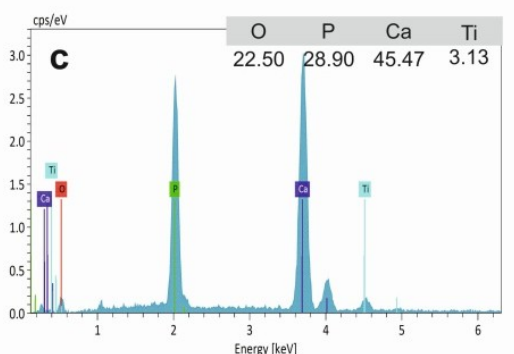

\section{pH 10.0}

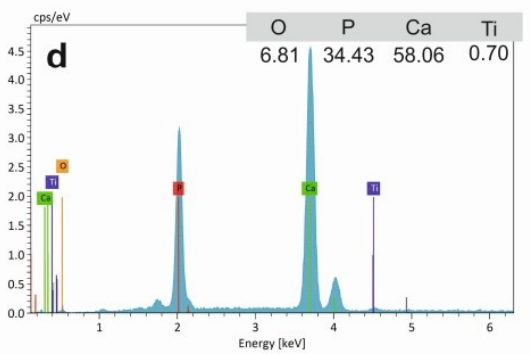

\section{pH 10.5}
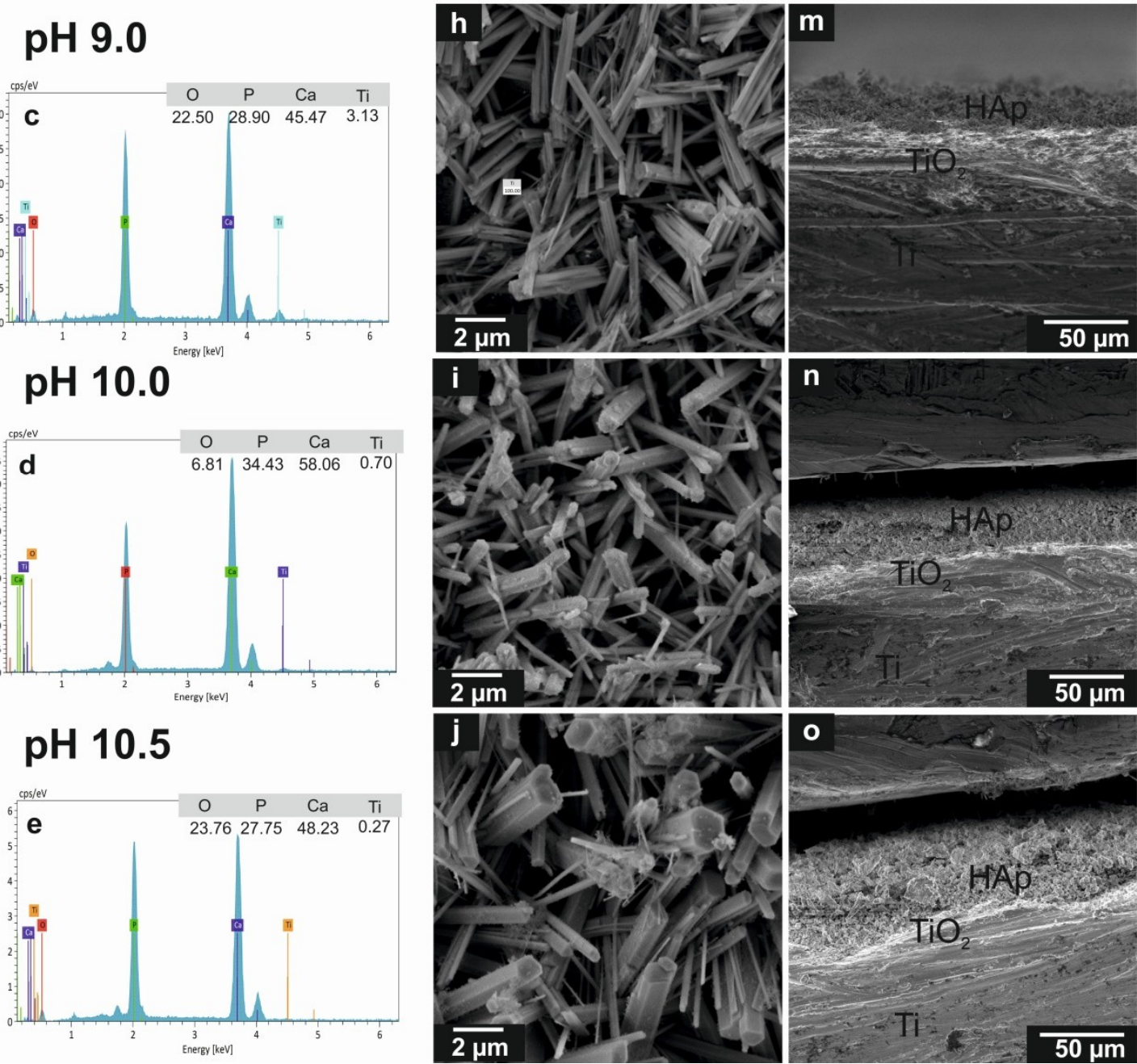

Figure 1. The morphological and elemental analysis of HAp coatings. (a-e) EDS spectra and (f-je top view SEM images showing the morphological evolution of calcium phosphate crystals synthesized on $\mathrm{Ti} / \mathrm{TiO}_{2}$ through hydrothermal method for different ammonium hydroxide concentrations. Panels (k-o) show the cross-sectional images of HAp coatings synthesized at different $\mathrm{pH}$. 
(a)

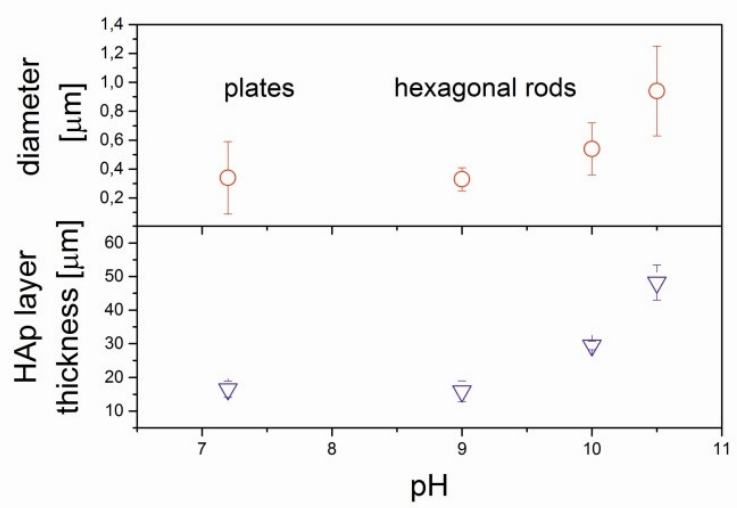

(b)

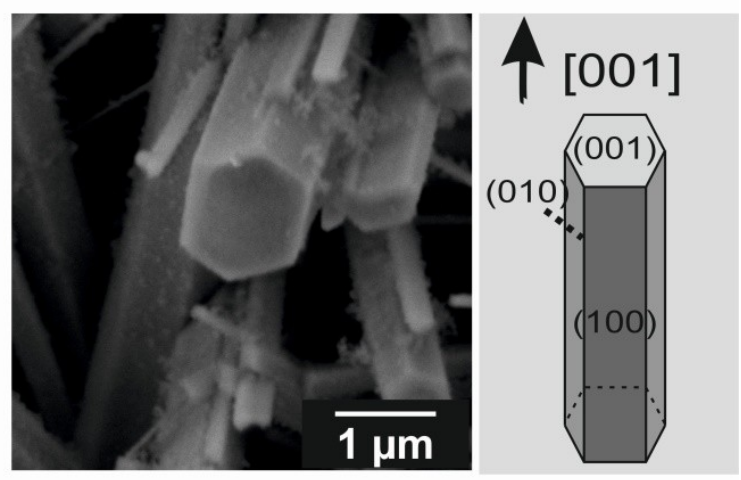

Figure 2. (a) Effect of ammonium hydroxide concentration on the size of synthesized crystals and layer thickness. (b) High magnification SEM image highlighting the shape of an individual HAp crystal for sample with the highest concentration of $\mathrm{NH}_{4} \mathrm{OH}$.

(a)

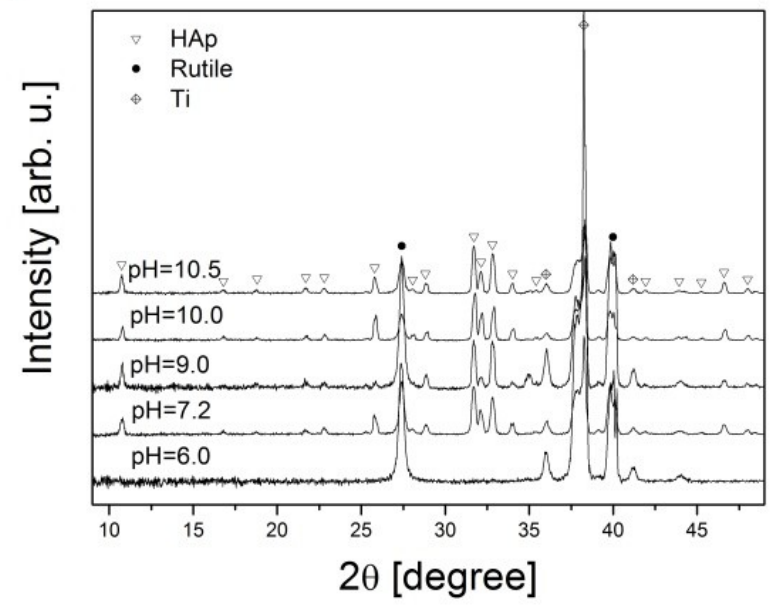

(b)

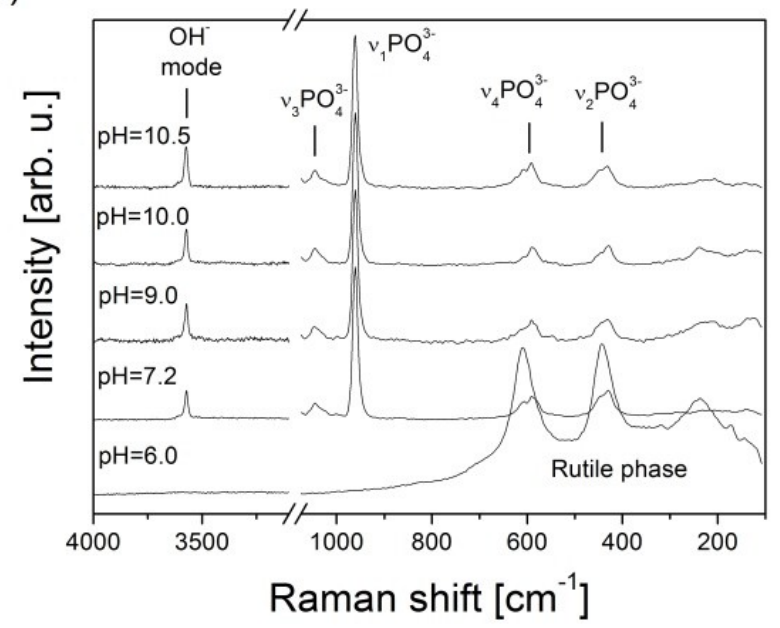

Figure 3. (a) XRD patterns and (b) Raman spectra of HAp crystals synthesized at different $\mathrm{NH}_{4} \mathrm{OH}$ concentrations on titanium substrate. 
The XRD results were confirmed by Raman spectroscopy (Figure 3b). Samples synthesized at $\mathrm{pH}=$ 6.0 revealed Raman bands characteristic only for titanium oxide in rutile phase [34]. For other samples we observed the characteristic bands for HAp phase [35], i.e., vibrations of $\mathrm{PO}_{4}{ }^{3-}$ groups observed in the position of $390-470 \mathrm{~cm}^{-1}$ ( $\vee 2$ mode assigned to the doubly degenerate bending vibration of $\mathrm{O}-\mathrm{P}-\mathrm{O}$ bonds), $560-625 \mathrm{~cm}^{-1}$ ( $\vee 4$ frequency resulting from the triply degenerate bending mode of $\mathrm{O}-\mathrm{P}-\mathrm{O}$ bonds), $961 \mathrm{~cm}^{-1}$ ( $v 1$ mode assigned to the symmetric stretching vibration of $\mathrm{P}-\mathrm{O}$ bond), $1010-1100 \mathrm{~cm}^{-1}$ ( $\vee 3$ mode attributed to the triply degenerate stretching vibration of $\mathrm{P}-\mathrm{O}$ bonds), and $\mathrm{OH}^{-}$symmetric stretching mode in the high wavenumber region at $3575 \mathrm{~cm}^{-1}$.

More details of the chemical composition of our samples were obtained by PIXE method. A unique opportunity offered by PIXE measurements is a non-destructive determination of the element concentration within a sample up to ppm level. PIXE offers high element sensitivities for transition elements with medium atomic mass and for that reason it is a very useful tool for monitoring changes in concentration of calcium phosphates [36]. Figure 4 shows the comparison of PIXE spectra obtained for the HAp coatings grown at different $\mathrm{pH}$ values. Peaks at energies $2.013 \mathrm{keV}$ and $3.692 \mathrm{keV}$ indicate $\mathrm{K}_{\alpha}$ lines of phosphorous and calcium, respectively. In addition, the strong peaks observed between 4 and $5 \mathrm{keV}$ energy, and week peak around $2.7 \mathrm{keV}$, testify to the presence of titanium. The results show the presence of both calcium and phosphorous species in all examined samples, even samples synthesized at $\mathrm{pH}=6.0$. The quantity of $\mathrm{Ca}$ and $\mathrm{P}$ for sample synthesized at lowest $\mathrm{pH}$ was relatively small and was significantly enhanced when the $\mathrm{pH}$ increased. The reduction of titanium contribution was also detected. PIXE spectra demonstrate that the content of calcium and phosphorus in the samples increases with $\mathrm{pH}$, which indirectly indicates an increase in the amount of the hydroxyapatite phase. These data confirm prior observations, showing the increase of HAp thickness with the increasing ammonia concentration.

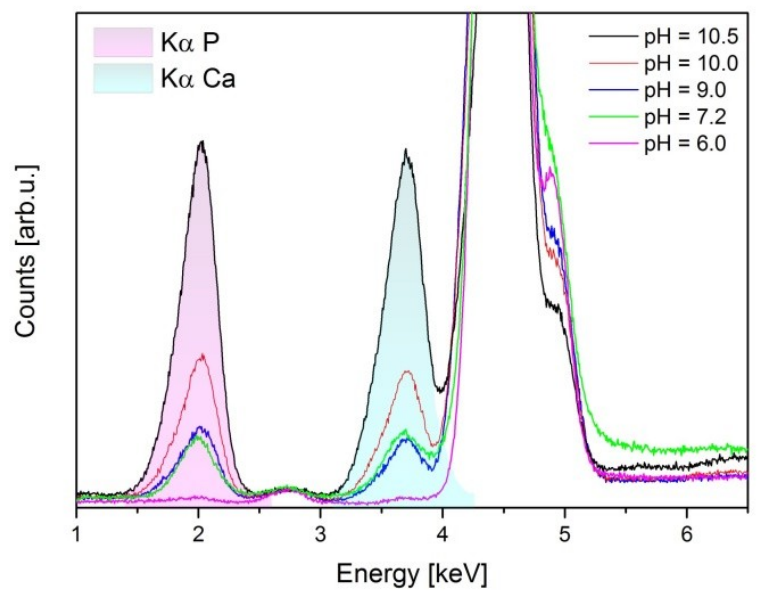

Figure 4. PIXE results for titanium samples hydrothermally treated in calcium phosphate solution with various $\mathrm{pH}$.

\section{Discussion}

To date, crystallization of HAp by chelate decomposition method has allowed to control the morphology of powders. The $\mathrm{pH}$ changes of reaction solution were carried out by various alkalizing agents, such as $\mathrm{NaOH}, \mathrm{KOH}$ or $\mathrm{NH}_{4} \mathrm{OH}[20,21,24,25]$. It was shown that increasing the $\mathrm{pH}$ leads to a reduction in particles size. Arce et al. presented a shape evolution from plate like monetite at $\mathrm{pH}=5.0$ to the tiny elongated HAp specimens at $\mathrm{pH}=9.0$ [21]. Chen et. al. synthesized fluorapatite crystals with various morphologies in the presence of different chelating reagents at various $\mathrm{pH}$ conditions [20]. They showed that the shape of the particles evolved from flower-like crystals at $\mathrm{pH}=3.6$ to nanowires at $\mathrm{pH}=10.0$. Similar results were obtained by Lak et al., who synthesized at $\mathrm{pH}=12$ dandelion-like 
HAp nanostructures with high specific surface area [13]. The size reduction of crystals is explained on the basis of selective adsorption of $\mathrm{OH}^{-}$ions under high $\mathrm{pH}$ conditions.

The morphology of crystals grown during heterogeneous crystallization of coatings is controlled not only by the chemicals involved in the reactions but also through the interface on which the apatite layer is deposited. The possibility of obtaining HAp coatings on various metallic substrates using chelate decomposition synthesis route was first shown by Fujishiro et al. [24,25]. Since then, various seeding layers on the titanium substrate have been used in order to induce controlled growth of HAp crystals [26-28]. In the present study, we obtained hydroxyapatite coatings composed of hexagonal rods with a c-axis orientation using the appropriate concentration of $\mathrm{NH}_{4} \mathrm{OH}$ directly on the titanium substrate. We also observed that there is $\mathrm{pH}$ of reaction solution below which the nucleation and subsequent HAp crystal growth are restrained. These results suggest that the use of strong chelating ligand, such as EDTA together with $\mathrm{pH}$ adjusting reagent, such as ammonia enables facile control over the morphology of HAp crystals grown on titanium substrate during hydrothermal process. In general, the driving force for crystallization from the solution is supersaturation, which under the hydrothermal conditions is controlled by the complexing compound, the initial $\mathrm{pH}$ of the solution and the temperature. Initially, EDTA wraps around the calcium ion to form a stable chelate ring and depletes the solution into free $\mathrm{Ca}^{2+}$. The reduction of free $\mathrm{Ca}^{2+}$ ions induces an inhibitory effect on the nucleation of HAp. However, the tendency of the Ca-EDTA complex to dissociate in solutions increases with an increasing temperature. This means that with an increasing reaction temperature under hydrothermal conditions, the stability of Ca-EDTA complex is weakened and the $\mathrm{Ca}^{2+}$ ions are released into solution. $\mathrm{Ca}^{2+}$ ions then react with the negative phosphate and hydroxyl ions in the medium to form hydroxyapatite crystals. The stability of Ca-EDTA is also $\mathrm{pH}$ dependent and for an acidic environment, the chemical equilibrium is shifted towards complex dissociation, hence more calcium ions are released into the medium under given temperature condition. At high supersaturation the rapid nucleation generates a large number of nuclei which tend to grow to low dimension particles. In contrast, a low degree of supersaturation promotes crystal growth over nuclei formation. The slow growth rate causes the HAp crystal to form hexagonal rods due to intrinsic factor which is hexagonal symmetry of crystalline hydroxyapatite. This is the case of high concentrations of ammonia for which the stability of Ca-EDTA is enhanced.

In our research, the HAp crystals grow on the titanium substrate. Modification of titanium and formation of the oxide layer results in the appearance of functional groups such as $-\mathrm{OH}$ which serve as active sites to promote the heterogeneous formation of HAp nuclei. However, at a solution of $\mathrm{pH}$ below 7, the HAp crystals on the titanium substrate did not grow. We speculate that this is due to the surface charge of titanium oxide in aqueous medium. The isoelectric point (IEP) for the surface of titanium oxide varies between 5.0 and 6.5 (depending on the crystal phase) [32]. This means that when the $\mathrm{pH}$ of solution is less than 6.5 the electrostatic interaction between the surface of the oxide and the ions in the medium is weakened, resulting in nucleation inhibition.

\section{Conclusions}

In conclusion, our study shows the effect of $\mathrm{NH}_{4} \mathrm{OH}$ concentration (resulting in $\mathrm{pH}$ variations) on the hydrothermal crystal growth of hydroxyapatite directly on the $\mathrm{Ti} / \mathrm{TiO}_{2}$ substrate without any additional seeding layer. We observe a $\mathrm{pH}$ limit for which the precipitation of HAp on titanium occurs. In acidic environments $(\mathrm{pH}<7)$, this study shows that the crystals growth of HAp on $\mathrm{Ti} / \mathrm{TiO}_{2}$ is inhibited. A further increase in $\mathrm{pH}(\mathrm{pH}>7)$ leads to the growth of HAp crystals on the $\mathrm{Ti} / \mathrm{TiO}_{2}$ substrate. Crystal size and shape evolve from irregular plates into well-defined rods with hexagonal symmetry. Structural studies confirm the presence of hydroxyapatite. Our results also show that $\mathrm{NH}_{4} \mathrm{OH}$ has a measurable influence on the coating thickness. With the increase of $\mathrm{NH}_{4} \mathrm{OH}$ concentration we observe an increase in thickness of the HAp layer, also indicating an increase of the crystal growth rate. We demonstrate that the morphological and structural characteristics of crystals growth on the $\mathrm{Ti} / \mathrm{TiO}_{2}$ surface can be controlled by a simple change of the $\mathrm{pH}$ of the starting solution. 
Author Contributions: Conceptualization, K.S.; methodology, K.S., M.P. and J.L.; investigation, K.S. and M.S.; writing—original draft preparation, K.S.; writing — review and editing, K.S. and M.M.; supervision, M.M.

Funding: This research received no external funding.

Conflicts of Interest: The authors declare no conflict of interest.

\section{References}

1. Olszta, M.J.; Cheng, X.; Jee, S.S.; Kumar, R.; Kim, Y.Y.; Kaufman, M.J.; Douglas, E.P.; Gower, L.B. Bone structure and formation: A new perspective. Mater. Sci. Eng. R 2007, 58, 77-116. [CrossRef]

2. Dorozhkin, S.V. Calcium orthophosphate deposits: Preparation, properties and biomedical applications. Mater. Sci. Eng. C 2015, 55, 272-326. [CrossRef] [PubMed]

3. Bar-On, B.; Wagner, H.D. Structural motifs and elastic properties of hierarchical biological tissues-A review. J. Struct. Biol. 2013, 183, 149-164. [CrossRef] [PubMed]

4. Sadat-Shojai, M.; Khorasani, M.T.; Dinpanah-Khoshdargi, E.; Jamshidi, A. Synthesis methods for nanosized hydroxyapatite with diverse structures. Acta Biomater. 2013, 9, 7591-7621. [CrossRef] [PubMed]

5. Xu, H.; Geng, X.; Liu, G.; Xiao, J.; Li, D.; Zhang, Y.; Zhu, P.; Zhang, C. Deposition, nanostructure and phase composition of suspension plasma-sprayed hydroxyapatite coatings. Ceram. Int. 2016, 42, 8684-8690. [CrossRef]

6. Fomin, A.; Fomina, M.; Koshuro, V.; Rodionov, I.; Zakharevich, A.; Skaptsov, A. Structure and mechanical properties of hydroxyapatite coatings produced on titanium using plasma spraying with induction preheating. Ceram. Int. 2017, 43, 11189-11196. [CrossRef]

7. Mayr, H.; Ordung, M.; Ziegler, G. Development of thin electrophoretically deposited hydroxyapatite layers on TiAl6V4 hip prosthesis. J. Mater. Sci. 2006, 41, 8138-8143. [CrossRef]

8. Nathanael, A.J.; Sabari Arul, N.; Ponpandian, N.; Mangalaraj, D.; Chen, P.C. Nanostructured leaf like hydroxyapatite $/ \mathrm{TiO}_{2}$ composite coatings by simple sol-gel method. Thin Solid Films 2010, 518, 7333-7338. [CrossRef]

9. Ivanova, A.A.; Surmeneva, M.A.; Surmenev, R.A.; Depla, D. Influence of deposition conditions on the composition, texture and microstructure of RF-magnetron sputter-deposited hydroxyapatite thin films. Thin Solid Films 2015, 591, 368-374. [CrossRef]

10. Suchanek, K.; Bartkowiak, A.; Gdowik, A.; Perzanowski, M.; Kac, S.; Szaraniec, B.; Suchanek, M.; Marszałek, M. Crystalline hydroxyapatite coatings synthesized under hydrothermal conditions on modified titanium substrates. Mater. Sci. Eng. C 2015, 51, 57e63. [CrossRef]

11. Roeder, R.K.; Converse, G.L.; Leng, H.; Yue, W. Kinetic effects on hydroxyapatite whiskers synthesized by the chelate decomposition method. J. Am. Ceram. Soc. 2006, 89, 2096-2104. [CrossRef]

12. Zhu, R.; Yu, R.; Yao, J.; Wang, D.; Ke, J. Morphology control of hydroxyapatite through hydrothermal process. J. Alloys Compd. 2008, 457, 555-559. [CrossRef]

13. Lak, A.; Mazloumi, M.; Mohajerani, M.; Kajbafvala, A.; Zanganeh, S.; Arami, H.; Sadrnezhaad, S.K. Self-assembly of dandelion-like hydroxyapatite nanostructures via hydrothermal method. J. Am. Ceram. Soc. 2008, 91, 3292-3297. [CrossRef]

14. Xie, R.; Feng, Z.; Li, S.; Xu, B. EDTA-Assisted self-assembly of fluoride-substituted hydroxyapatite coating on enamel substrate. Cryst. Growth Des. 2011, 11, 5206-5214. [CrossRef]

15. Neira, I.S.; Guitián, F.; Taniguchi, T.; Watanabe, T.; Yoshimura, M. Hydrothermal synthesis of hydroxyapatite whiskers with sharp faceted hexagonal morphology. J. Mater. Sci. 2008, 43, 2171-2178. [CrossRef]

16. Neira, I.S.; Kole'ko, Y.; Lebedev, O.I.; Van Tendeloo, G.; Gupta, H.S.; Guitian, F.; Yoshimura, M. Effective morphology control of hydroxyapatite crystals via hydrothermal synthesis. Cryst. Growth Des. 2009, 9, 466-474. [CrossRef]

17. Wu, S.C.; Tsou, H.K.; Hsu, H.C.; Hsu, S.K.; Liou, S.P.; Ho, W.F. A hydrothermal synthesis of eggshell and fruit waste extract to produce nanosized hydroxyapatite. Ceram. Int. 2013, 39, 8183-8188. [CrossRef]

18. Kimn, I.Y.; Ohtsuki, C. Hydroxyapatite formation from calcium carbonate single crystal under hydrothermal condition: Effects of processing temperature. Ceram. Int. 2016, 42, 1886-1890. [CrossRef]

19. Yan, L.; Li, Y.; Deng, Z.X.; Zhuang, J.; Sun, X. Surfactant-assisted hydrothermal synthesis of hydroxyapatite nanorods. Int. J. Inorg. Mater. 2001, 3, 633-637. [CrossRef] 
20. Chen, M.; Jiang, D.; Li, D.; Zhu, J.; Li, G.; Xie, J. Controllable synthesis of fluorapatite nanocrystals with various morphologies: Effects of $\mathrm{pH}$ value and chelating reagent. J. Alloys Compd. 2009, 485, 396-401. [CrossRef]

21. Arce, H.; Montero, M.L.; Saenz, A.; Castano, V.M. Effect of $\mathrm{pH}$ and temperature on the formation of hydroxyapatite at low temperatures by decomposition of a Ca-EDTA complex. Polyhedron 2004, 23, 1897-1901. [CrossRef]

22. Taheri, M.M.; Abdul Kadir, M.R.; Shokuhfar, T.; Hamlekhan, A.; Assadian, M.; Shirdar, M.R.; Mirjalili, A. Surfactant-assisted hydrothermal synthesis of Fluoridated Hydroxyapatite nanorods. Ceram. Int. 2015, 41, 9867-9872. [CrossRef]

23. Tombacz, E. pH-dependent surface charging of metal oxides. Period. Polytech. Chem. Eng. 2009, 53, 77. [CrossRef]

24. Fujishiro, Y.; Sato, T.; Okuwaki, A. Coating of hydroxyapatite on metal plates using thermal dissociation of calcium-EDTA chelate in phosphate solutions under hydrothermal conditions. J. Mater. Sci. Mater. Med. 1995, 6, 172-176. [CrossRef]

25. Fujishiro, Y.; Fujimoto, A.; Sato, T.; Okuwaki, A. Coating of hydroxyapatite on titanium plates using thermal dissociation of Calcium-EDTA Chelate Complex in phosphate solutions under hydrothermal conditions. J. Colloid Interface Sci. 1995, 173, 119-127. [CrossRef]

26. Lu, Z.Z.; Xu, H.Y.; Xin, M.D.; Li, K.W.; Wang, H. Induced growth of (0001)-oriented hydroxyapatite nanorod arrays on ZnO-seeded glass substrate. J. Phys. Chem. C 2010, 114, 820-825. [CrossRef]

27. Chen, W.; Long, T.; Guo, Y.-J.; Zhu, Z.-A.; Guo, Y.-P. Hydrothermal synthesis of hydroxyapatite coatings with oriented nanorod arrays. RSC Adv. 2014, 4, 185. [CrossRef]

28. Shen, J.; Qi, Y.; Jin, B.; Wang, X.; Hu, Y.; Jiang, Q. Control of hydroxyapatite coating by self-assembled monolayers on titanium and improvement of osteoblast adhesion. J. Biomed. Mater. Res. B Appl. Biomater. 2017, 105, 124-135. [CrossRef]

29. Li, H.; Mei, L.; Liu, H.; Liu, Y.; Liao, L.; Kumar, R.V. Growth mechanism of surfactant-free size-controlled luminescent hydroxyapatite nanocrystallites. Cryst. Growth Des. 2017, 17, 2809-2815. [CrossRef]

30. Kokubo, T.; Pattanayak, D.K.; Yamaguchi, S.; Takadama, H.; Matsushita, T.; Kawai, T.; Takemoto, M.; Fujibayashi, S.; Nakamura, T. Positively charged bioactive Ti metal prepared by simple chemical and heat treatment. J. R. Soc. Interface 2010, 7, 503-513. [CrossRef]

31. Pattanayak, D.K.; Yamaguchi, S.; Matsushita, T.; Nakamura, T.; Kokubo, T. Apatite forming ability of titanium in terms of $\mathrm{pH}$ of the exposed solution. J. R. Soc. Interface 2012, 9, 2145-2155. [CrossRef]

32. Kosmulski, M. Compilation of PZC and IEP of sparingly soluble metal oxides and hydroxides from literature. Adv. Colloid. Interface Sci. 2009, 152, 14-25. [CrossRef]

33. Koutsopoulos, S. Synthesis and characterization of hydroxyapatite crystals: A review study on the analytical methods. J. Biomed. Mater. Res. 2002, 62, 600-612. [CrossRef]

34. Hardcastle, F.D.; Ishihara, H.; Sharma, R.; Biris, A.S. Photoelectroactivity and Raman spectroscopy of anodized titania $\left(\mathrm{TiO}_{2}\right)$ photoactive water-splitting catalysts as a function of oxygen-annealing temperature. J. Mater. Chem. 2011, 21, 6337-6345. [CrossRef]

35. Tsuda, H.; Arends, J. Orientational micro-Raman spectroscopy on hydroxyapatite single crystals and human enamel crystallites. J. Dent. Res. 1994, 73, 1703-1710. [CrossRef]

36. Heimann, R.B.; Ntsoane, T.P.; Pineda-Vargas, C.A.; Przybylowicz, W.J.; Topić, M. Biomimetic formation of hydroxyapatite investigated by analytical techniques with high resolution. J. Mater. Sci. Mater. Med. 2008, 19, 3295-3302. [CrossRef]

(C) 2019 by the authors. Licensee MDPI, Basel, Switzerland. This article is an open access article distributed under the terms and conditions of the Creative Commons Attribution (CC BY) license (http:/ / creativecommons.org/licenses/by/4.0/). 